\title{
Cost of Delivering Secondary Healthcare Through the Public Sector in India
}

\author{
Shankar Prinja ${ }^{1} \odot$ - Akashdeep Singh Chauhan ${ }^{1} \cdot$ Pankaj Bahuguna $^{1} \cdot$ Sakhtivel Selvaraj $^{2} \cdot$ V. R. Muraleedharan ${ }^{3}$. \\ Thiagarajan Sundararaman ${ }^{4}$
}

Published online: 29 August 2019

(c) The Author(s) 2019

\begin{abstract}
Background Government spending on provision of secondary healthcare has increased four-fold (in real terms) over the last decade in India. The evidence on the cost of secondary care to the health system is limited. The present study estimates the total and unit cost of services at community health centres (CHCs) and district hospitals (DHs) across India.

Methods The present study was undertaken in 19 CHCs and ten DHs across the four Indian states of Himachal Pradesh, Tamil Nadu, Kerala and Odisha to assess the economic cost of health services using a bottom-up methodology. Data on annual consumption of both capital and recurrent resources, spent in the provision of health services during the financial year of 2014-2015, were collected. Capital expenditure was annualised and shared resources were allocated to each of the shared activities using appropriate statistics.

Results The mean annual costs of providing services at the CHC and DH level were 17 million Indian rupees (₹) (\$US0.27 million) and ₹147 million (\$US2.3 million), respectively. More than half of this annual cost was attributed to salaries (57\% and 62\% for CHC and DH level, respectively) and curative care (60\% and 65\%, respectively). At CHCs, the unit cost ranged from ₹134 (95\% confidence interval [CI] 104-160) for an outpatient consultation to ₹3833 (95\% CI 2668-5839) for institutional delivery. Similarly, at DH level, the unit cost varied from ₹183 (95\% CI 124-248) for an outpatient consultation in an orthopaedics department to ₹4764 (95\% CI 3268-6960) for an operation.

Conclusion The estimates from the present study may help generate benchmarks to aid in setting up provider payment rates and be used in future economic evaluations.
\end{abstract}

\section{Introduction}

The Government healthcare system in India is organised into three tiers of primary-, secondary- and tertiary-level healthcare based on the level of services delivered [1].

Electronic supplementary material The online version of this article (https://doi.org/10.1007/s41669-019-00176-9) contains supplementary material, which is available to authorized users.

Shankar Prinja

shankarprinja@gmail.com

1 Department of Community Medicine, School of Public Health, Post Graduate Institute of Medical Education and Research, Chandigarh 160012, India

2 Public Health Foundation of India, New Delhi, India

3 Department of Humanities and Social Sciences, Indian Institute of Technology (Madras), Chennai, India

4 School of Health Systems Studies, Tata Institute of Social Sciences, Deonar, Mumbai, India
The secondary level consists of community health centres (CHCs) and district hospitals (DHs), which act as referral units to primary-level facilities and are mainly involved in the provision of curative care with a small component of preventive care [2,3].

Traditionally, health systems across developing countries, including India, have been financed through supply-side financing mechanisms $[4,5]$. With the launch of a supplyside initiative in the form of the National Rural Health Mission (NRHM) in 2005, a large volume of resources was spent on the creation of new CHCs (65\% increase in the number of $\mathrm{CHCs}$ ) and strengthening old ones (15-60\% increase in the number of staff) across India during the period of 2005-2016 [6, 7]. Further, the Government of India has also introduced demand-side financing models in the form of taxfunded publicly financed health insurance schemes across Indian states [8-10]. Due to these initiatives, government spending on secondary healthcare has increased by $7 \%$, from $15 \%$ (39.319 Indian rupees [₹]) to 22\% (₹307.89 billion) of the overall public sector spending for healthcare in India 


\section{Key Points for Decision Makers}

The present study fills the current gap in evidence regarding the cost of secondary healthcare services delivered through public sector health facilities in India.

The unit cost estimates assessed in this study could serve as a benchmark to begin price negotiations with healthcare providers under the recently launched health insurance scheme Pradhan Mantri Jan Aarogya Yojana (AB-PMJAY), the largest in India.

Cost estimates from this study can be used to carry out cost-effectiveness analysis for evidence-based decisionmaking as part of the recently launched Health Technology Assessment in India (HTAIn).

from 2004 to 2005 to 2014-2015 [11, 12]. However, despite this increase in spending on secondary healthcare, there is little evidence available on the total and unit costs of health services at secondary-level facilities in India.

It is equally interesting to observe that the reimbursement packages under government-funded health insurance schemes are based on expert opinion that rely on existing prices or reimbursement rates with little empirically assessed evidence on cost of care [13]. Estimates involving the unit cost of health services, especially at the level of secondary care, can be used to empirically derive the package rates for various disease conditions. Further, if the government were to scale up healthcare services substantially, estimates of total cost and its input-wise distribution can provide vital information for allocating additional resources. Finally, while the debate on whether to choose demandside or supply-side financing for the health system of India continues to grow, estimates of health system costs across various levels of healthcare delivery can provide evidence in terms of which model is more efficient and what the level of additional investment should be [14].

Regardless of the seeming need for information on the cost of provision of healthcare from a health system perspective, the available evidence is insufficient in terms of being either outdated or not comprehensive in terms of covering the range of services or a significantly wide geographical area in the selection of facilities. Estimates generated by the World Health Organization (WHO; 2005) and National Commission on Macroeconomics and Health (NCMH; 2005) are outdated $[15,16]$ Secondly, estimates of healthcare expenditure generated by the National Health Accounts (NHA) are based on financial costs rather than a more complete economic costing $[11,12]$. Thirdly, although there are a few primary studies on the cost of secondary healthcare, these are specifically focused on north Indian states [17-19].
It is difficult to generalise the cost estimates from these studies to a pan-Indian context due to variability across states in terms of availability of infrastructure and utilisation patterns. Considering this critical gap, the present study was designed to estimate the total and unit costs of delivering healthcare services at the level of CHCs and DHs. In addition, distribution of cost in terms of the input, level and type of services was also assessed. The latter was relevant to any decision regarding programmes to improve the efficiency of healthcare services.

\section{Materials and Methods}

\subsection{Study Area}

The present study was carried out in the four diverse states of Himachal Pradesh (HP), Tamil Nadu (TN), Kerala and Odisha. These states were selected based on health system performance, availability of health system infrastructure/ human resources and service utilisation in addition to geographic location. The states of Kerala and TN represented the southern region as well as the states with the best health indicators and well-developed health infrastructure [20]. In comparison to these states, Odisha represented a state with poor health infrastructure and below average health indicators [21]. HP represented a hilly state in North India with population coverage norms, government spending, availability of healthcare infrastructure and utilisation rates different from those in the rest of India [22]. HP is the state with the highest government health spending per capita in India [23] and has one of the highest utilisation levels of public healthcare facilities for inpatient care compared with the rest of India [24]. A normal $\mathrm{CHC}$ caters to a population of 0.12 million, whereas in hilly areas a $\mathrm{CHC}$ caters to a population of 80,000 [2]. Furthermore, HP is one of the states with surplus availability of human resources, i.e. medical and paramedical staff, at the DH level [25].

A multistage stratified random sampling was followed for the selection of the health facilities across the four states. In the first stage, districts within each of the states were divided into three strata based on a ranking matrix, considering various socioeconomic and demographic indicators, developed by International Institute of Population Sciences (IIPS) in Mumbai in 2006. A district was then selected for the present study based on simple random sampling from each strata [26]. In case of TN and Odisha, however, the overall districts were divided into 2 strata, from which the districts were randomly selected. In the second stage, as each district consisted of one $\mathrm{DH}$, that $\mathrm{DH}$ was selected for the study. In addition, $15 \%$ of the CHCs in each of the selected districts were selected randomly. Finally, a total of $19 \mathrm{CHCs}$ $(\mathrm{HP}=3$, Odisha $=7, \mathrm{TN}=3$ and Kerala $=6)$ and ten DHs 
(three each in HP and Kerala and two each in Odisha and $\mathrm{TN}$ ) were selected across the four states.

\subsection{Facility Definition}

As per Indian Public Health Standards (IPHS), CHCs cater to a population of 80,000-120,000 (depending on the region and terrain), have 30 beds and have at least four medical specialists in medicine, surgery, paediatrics and gynaecology, along with other medical and paramedical staff. CHCs have an operating theatre, an X-ray, a labour room and laboratory facilities and serve as a referral centre for primary health centres (PHCs) within the block and also provide healthcare facilities for obstetric care and specialist consultations [2].

DHs have a bed capacity of 75-500 beds, and serve as a main hub for the provision of secondary care for a district of a defined geographical area containing a defined population. Specialists from the fields of medicine, surgery, orthopaedics, paediatrics, ear nose throat (ENT), ophthalmology, gynaecology and obstetrics, pulmonary medicine, dentistry, dermatology, etc. provide outdoor patient department (OPD), indoor patient department (IPD) and emergency care. A DH also provides specialist services for specific areas such as accident and trauma care, dialysis, antiretroviral therapy, newborn intensive care and psychiatry. It is also supported by diagnostic, laboratory and radiological testing facilities [3].

\subsection{Data Collection}

A bottom-up costing method was used to assess the economic cost of health services [27, 28]. The first step for the cost assessment was identification of cost centres and their classification into primary/patient and secondary/supportive cost centres [29]. After this, data on both the capital and recurrent resource use incurred when delivering health services for each of the cost centres were collected for the financial year of 2014-2015.

A facility survey along with a review of facility maps and stock registers was undertaken to assess the space and the quantity of various items of capital equipment (and furniture items) present in the facility. Data on the quantity of drugs and consumables were assessed by reviewing the respective stock registers, vouchers and pharmacy records. Further, data on incentives paid to the beneficiaries (conditional cash transfers) under the various health schemes, untied funds, annual maintenance grants, etc. were obtained from the district health administration office (Civil Surgeon Office) of each district. Monthly expenditures relating to electricity, water, telephone, internet, petrol/diesel, etc. were obtained from the accounts office of each facility. Similarly, expenses related to the maintenance of equipment, laundry and dietetics were obtained from the routine account reports for the reference year. After identification of all inputs, data on service utilisation in the form of the number of outpatient consultations, hospitalisations, operations, etc. were captured by reviewing the routine records of the facility (such as outpatient registers, inpatient registers and other monthly reports). The data were collected by postgraduate-level qualified field investigators who were specifically trained for the cost data collection.

The prices of the equipment, drugs and consumables were obtained from the rate contract/procurement list of each State Government. In case of non-availability of the procurement price for any of these items, prices charged by local distributors or reported on relevant websites were considered. For estimating space costs, the current market rental price was assessed by interviewing the key informants. Due to non-availability of procurement prices for furniture and stationary items, market prices were used. Salary slips obtained from the accounts department were reviewed for data on annual wages paid to the staff. All prices reported in the paper are for the year 2014-2015.

Staff members both at the $\mathrm{CHC}$ and $\mathrm{DH}$ level were interviewed with a semi-structured interview schedule to assess the time being spent on various activities $[18,19]$. Specifically, they were asked about the time spent on both regular activities (outpatient consultation, inpatient care, operating theatre, etc.) and other activities (administration, meetings, etc.) carried out in a fixed time interval (weekly, monthly, annually, etc.). In case of a CHC, all of the doctors and 50\% of the nursing and paramedical staff were interviewed. For DHs, at least one specialist doctor and a medical officer were interviewed in each of the departments. In the case of there being more than one specialist or medical officer, one of each was randomly selected and interviewed. Further, one staff nurse (selected randomly) for each of a day and night shift in each of the functional cost centres was interviewed. The average life of the equipment was determined based on interviews with the staff members involved in working with that equipment.

\subsection{Data Analysis}

The expenditure on capital items (equipment, furniture, etc.) was annualised to arrive at the equivalent annual cost, taking into consideration the discount rate (to account for time preference for money, and inflation in future years) and the lifespan of the respective item [30]. A 3\% discount rate was used as per standard guidelines [31, 32]. Space costs were calculated by multiplying estimates of the floor size of rooms by local commercial rental prices for a similar space. The cost of the recurrent resources was estimated by multiplying the unit price with the quantity of respective resource. Proportional time spent by staff members in each of their joint activities was used as a statistic for apportioning their 
salaries towards particular activities. The cost of other resources (such as equipment, furniture, room space and expenditure on overheads) that were used to provide more than one service were also apportioned for specific services using appropriate apportioning statistics, as shown in Electronic Supplementary Material Table 1.

The mean annual cost at the CHC and DH level was estimated for the four states, along with its distribution among various inputs, levels of service and various specific services. The activities included under the each of the service classification levels, i.e. curative, indirect, preventive and promotive care, is provided in the Electronic Supplementary Material (appendices III and IV).

In addition to the total cost, the unit cost of specific services was also estimated. Calculation of the unit cost required combining all of the costs incurred for the provision of a particular service during a year divided by the total number of clients/patients who used the respective service in that year. The estimates of unit cost were simulated 999 times using the bootstrap method to calculate its $95 \%$ confidence limits. Unit costs were adjusted for capacity utilisation [31]. Since the utilisation varied across the health facilities, standardisation of the unit cost was carried out by using bed occupancy as the indicator for capacity utilisation. Bed occupancy rates both at the current of levels of utilisation and at $100 \%$ capacity utilisation were calculated based on actual data on the number of beds, average length of stay and patients admitted during the particular year. The costs incurred on recurrent resources, i.e. drugs, consumables, stationary and overheads, were adjusted for capacity utilisation, while keeping the expenditure incurred on fixed assets, i.e. human resources, space, equipment and furniture, constant.

The study was approved by the Institutional Ethics Committee, Post-Graduate Institute of Medical Education and Research, Chandigarh (reference number PGI/ IEC/2015/854). Administrative approval from the Department of Health of the respective State Governments and the Civil Surgeons of selected districts was obtained. Written informed consent was also obtained from each staff member for time allocation interviews.

\section{Results}

\subsection{Profile of Health Facilities}

Profiles of the health facilities covered in the selected four states of HP, Odisha, TN and Kerala are shown in the Electronic Supplementary Material (Tables 2a and 2b). In terms of population covered, the CHCs catered to an average population of 63,186 . The average number of beds was 20 and 226 and the doctor:bed ratio was 1:4 and1:9 for and $\mathrm{CHCs}$ and DHs, respectively. The average number of annual outpatient consultations were 202,277 and 52,707 at DH and $\mathrm{CHC}$ respectively. Similarly the number of inpatient admissions in DH and CHC per year was 30,595 and 1,981 respectively.

\subsection{Annual Cost}

The mean annual cost of providing health services at the level of CHC was ₹17 million (\$US0.27 million) and varied from ₹12.7 million (\$US0.209 million) in HP to ₹19.7 million (\$US0.324 million) in Kerala. Similarly, the mean annual cost at the DH level was ₹146 million (\$US2.3 million), ranging from ₹73 million (\$US1.2 million) in Odisha to ₹197 million (\$US3.1 million) in Kerala. Tables 1 and 2 show the input-wise distribution of mean annual cost across four states of India. Overall, more than half of the annual cost, both at the $\mathrm{CHC}$ and $\mathrm{DH}$ level, was attributed to salaries (human resources) (57\% and 62\%, respectively), followed by spending on drugs/consumables (25\% and $17 \%$ ), space (3\% and $8 \%$ ) and equipment/furniture (5\% and $3 \%$ ) (Fig. 1). In terms of variation across the four states, the relative share of salaries (of the total annual cost) varied from 47 to 67 and 40 to $67 \%$ at the level of CHCs and DHs, respectively (Tables 1 and 2). Similarly, the share of expenditure (of the total annual cost) on drugs and consumables varied from 11 to 29 and 11 to $34 \%$ for CHCs and DHs, respectively, across the four states.

More than half of the overall cost at the CHCs was attributed towards provisioning of curative services $(60 \%)$, followed by that on indirect services (28\%) and preventive/ promotive care (12\%) (Fig. 2). Similarly, around $65 \%$ of the overall cost was credited towards providing curative care at DHs (Fig. 2). State-specific distribution of the overall cost among services at the $\mathrm{CHC}$ and $\mathrm{DH}$ level is shown in Electronic Supplementary Material Tables 3 and 4, respectively.

In terms of distribution of specific services at CHCs, outpatient and inpatient care accounted for $34.4 \%$ and $13.7 \%$ of the total cost, respectively. This was followed by spending on routine administrative activities (9.6\%), support services (5.7\%), institutional deliveries/newborn care (5.4\%) and diagnostics (4.8\%) (Fig. 3). At the DH level, the medicine department (18\%) accounted for the highest cost, followed by expenditure on supportive activities (15.7\%) (Fig. 3). State-specific distribution of the overall cost among specific services at the CHC and DH level is shown in Electronic Supplementary Material Tables 5 and 6, respectively.

\subsection{Unit Costs}

Unit costs of specific services provided at CHCs across four states are shown in Table 3. Specifically, the overall per patient cost of an outpatient consultation was ₹134 (95\% confidence interval [CI] 104-160), ranging from ₹90 (95\% 

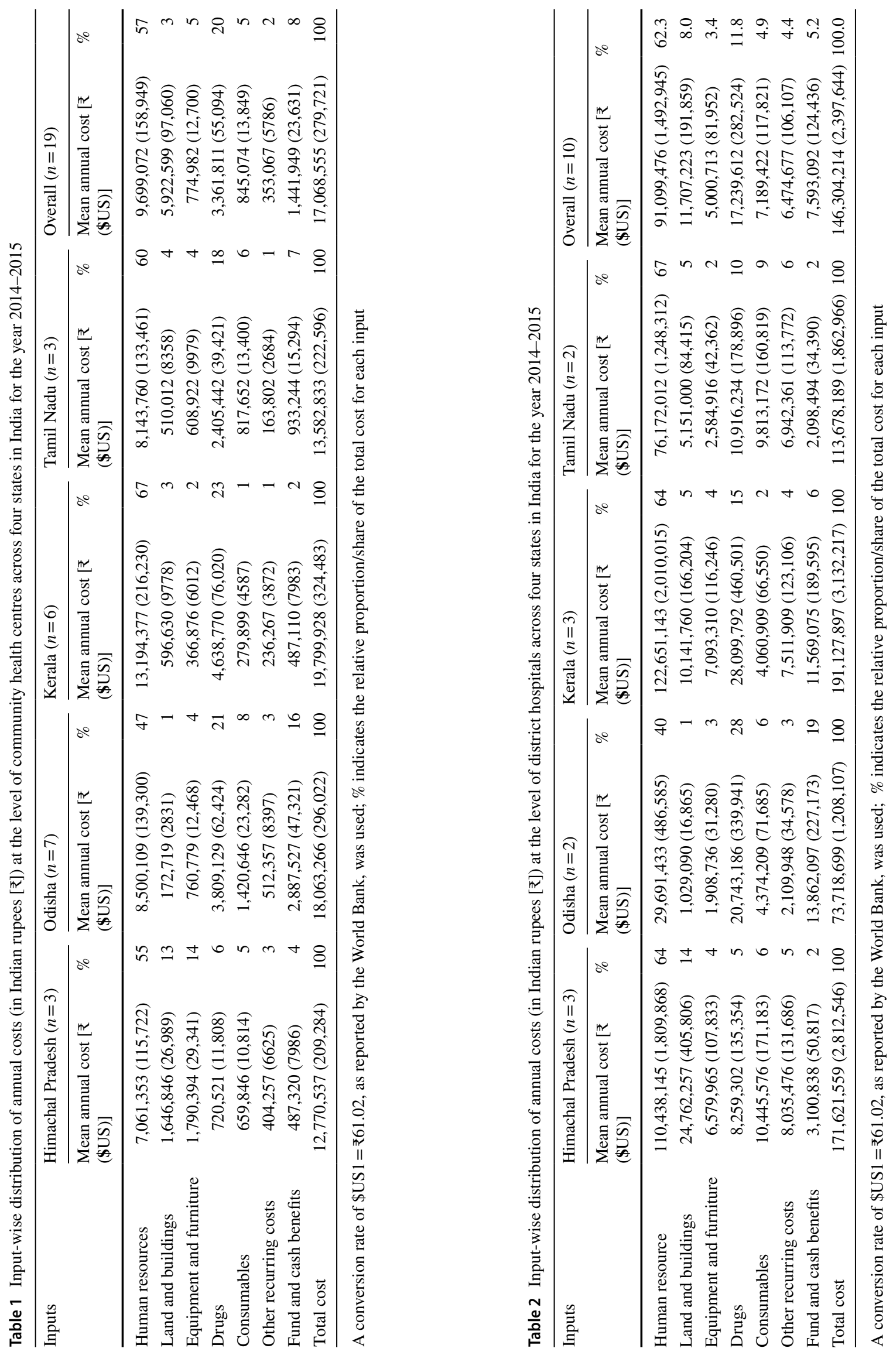


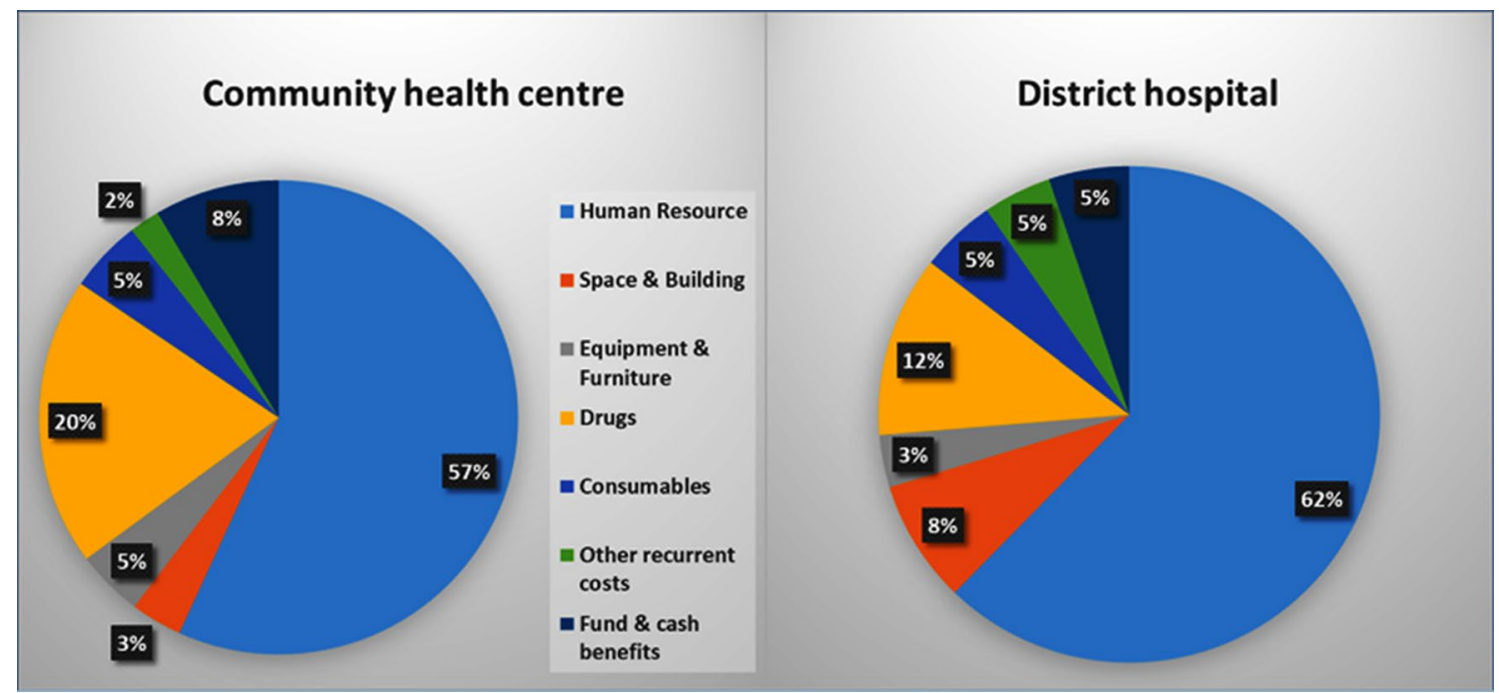

Fig. 1 Input-wise distribution of total annual costs incurred at the level of community health centres and district hospitals across four states in India for the year 2014-2015

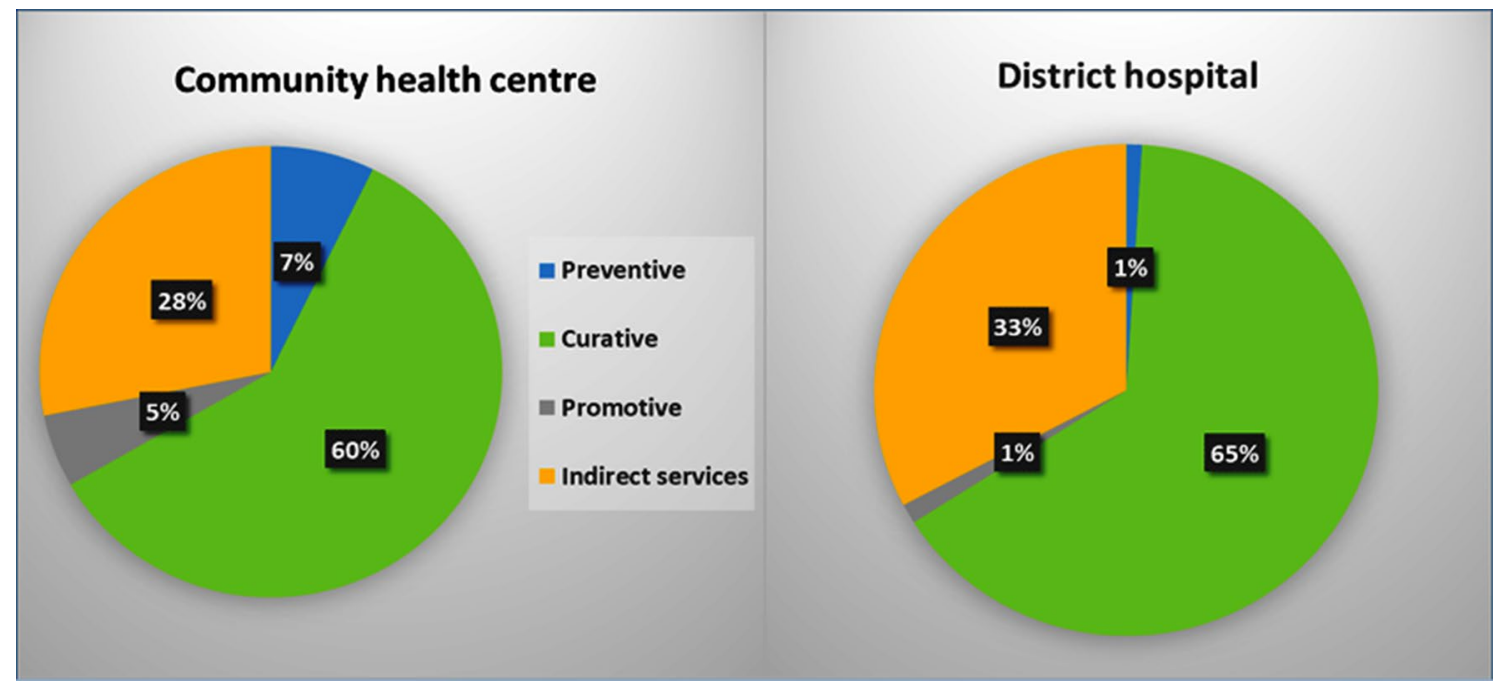

Fig. 2 Distribution of total annual costs by level of service at the level of community health centres and district hospitals across four states in India for the year 2014-2015

CI 52-153) in Kerala to ₹196 (95\% CI 150-281) in Odisha. Similarly, the cost per institutional delivery was ₹3833 (95\% CI 2668-5839) overall and varied from ₹2131 (95\% CI 1098-3043) in TN to ₹ 10,447 (95\% CI 2430-18,464) in HP. Further, the overall unit cost per antenatal care visit and vaccine dose was ₹366 (95\% CI 260-507) and ₹235 (95\% CI 166-315), respectively.

Table 4 summarises the unit cost incurred in the provision of an outpatient consultation for each of the specialities at the DH level. It can be seen that, at an overall level, the per patient consultation costs of ₹190 (95\% CI 134-248) and ₹183 (95\% CI 124-248) in the departments of dermatology and orthopaedics, respectively, were the lowest. In contrast, the unit costs for a consultation in the gynaecology (₹326 [95\% CI 198-462]) and dental departments (₹491 [95\% CI 241-776]) were the highest. Treatment using the Indian indigenous system of medicine was only provided at the DH in $\mathrm{TN}$ and the consultation cost varied from ₹21 to ₹99 for a doctor specialised in homeopathy or yoga, respectively.

Table 5 shows the unit cost estimates of inpatient care (in terms of per bed day cost) across the specialities at the DH level. The overall per bed day costs in the department of medicine (₹839 [95\% CI 321-1575]) and orthopaedics (₹892 [95\% CI 433-1615]) were the lowest (Table 5) and 


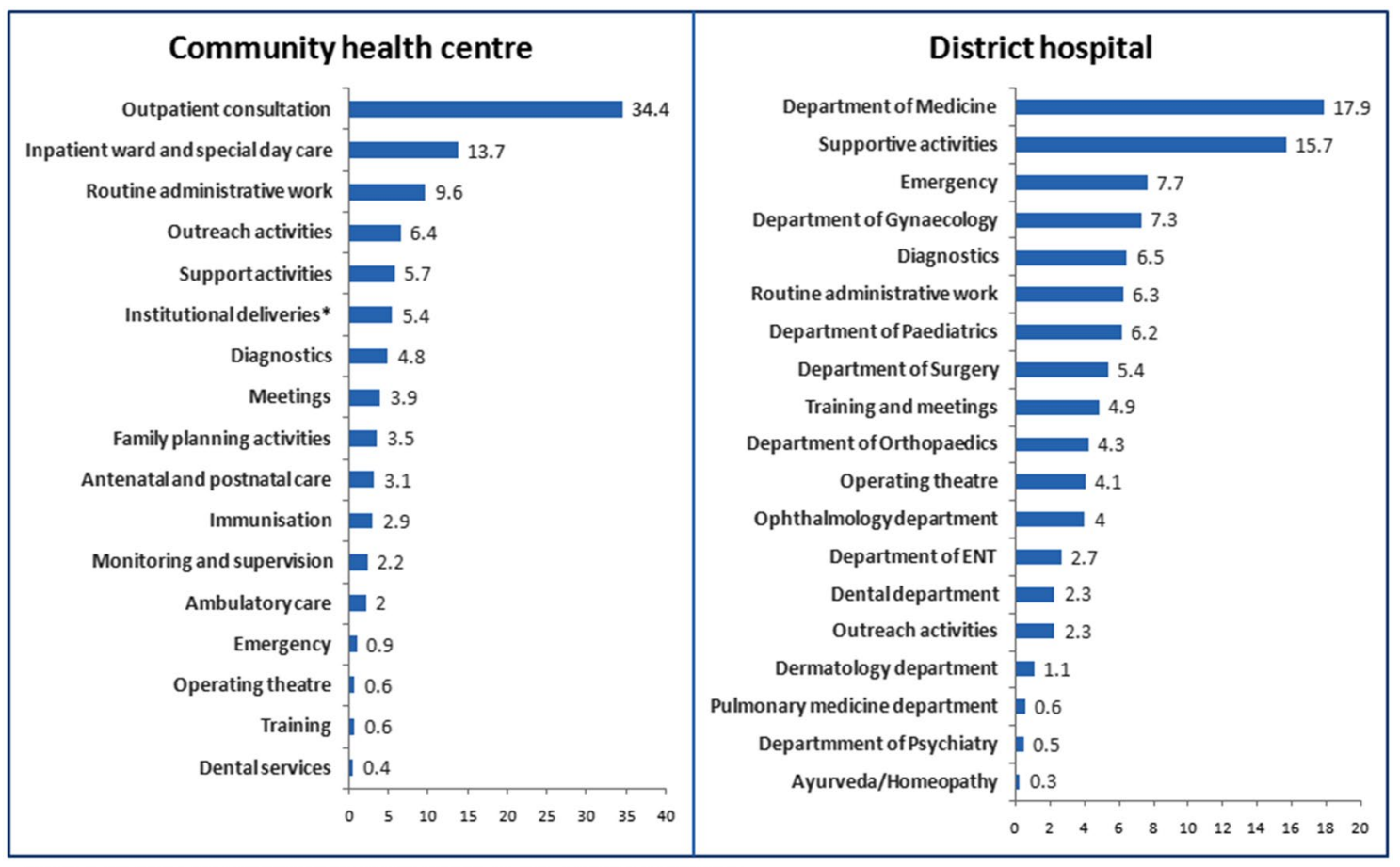

*Institutional deliveries include cost incurred on new-born care; ENT: Ear nose throat

Fig. 3 Distribution of the mean annual cost (\%) for specific health services at the level of community health centres and district hospitals across four states in India for the year 2014-2015

the overall per bed day costs of ₹1502 (95\% CI 742-2382) and ₹3090 (95\% CI 3090-3090) in the ENT and chest (pulmonary medicine) departments were the highest. The overall unit cost of performing an operation and treating a patient in the emergency ward was ₹4764 (95\% CI 3268-6960) and ₹1064 (95\% CI 479-1947), respectively.

\section{Discussion}

As India moves along the path of universal health coverage with an aim of providing affordable and quality healthcare to all, the Government of India has introduced demand-side financing mechanisms in the form of tax-funded health insurance schemes. While healthcare financing is being reformed from a supply-side to a demand-side financing system, provider payment rates are mostly determined based on expert opinion rather than empirically derived estimates. In addition, the Department of Health Research has set up Health Technology Assessment in India (HTAIn) to provide evidence for policy making by using cost-effectiveness analysis as a tool, as evidence on health system costs remains scarce. Hence, there is a critical need to determine the cost of healthcare services-whether to develop provider payment rates for financing, or to assess the efficiency of delivering health services by carrying out cost-effectiveness analysis. Our study fills the gap in the existing evidence by estimating the total and unit costs of providing health services at the secondary care level from a heterogeneous sample of four diverse states in India, which are reflective of diverse health systems in terms of availability of infrastructure, utilisation patterns, health indicators and overall development.

While the distribution of the mean operational annual cost of CHCs and DHs in terms of inputs and level of services was comparable with previous studies $[18,19]$, there were noticeable differences in the unit cost of various services, not only in the estimates of the previous studies but also among the states sampled in the present study. As the calculation of the unit cost of a particular service is dependent both on resource use as well as the number of persons who used the service, there was wide variation both in terms of infrastructure (including salary structure) and the extent of service utilisation across the four states (Electronic Supplementary Material Tables 2a and 2b). Specifically, the average monthly salary paid to a doctor in DHs ranged from ₹50,000 in TN to ₹120,000 in HP and the expenditure incurred on recurrent resources (drugs and consumables) varied from $₹ 1.38$ million in (HP) to ₹5.23 million (Odisha) at CHCs and from ₹18.7 million (HP) to ₹32 million (Kerala) at DHs. Similarly, considering OPD consultation for service utilization, annual outpatient attendance varied from 17,461 (HP) to 103,258 (Kerala) at CHCs and from 98,262 (Kerala) to $432,602(\mathrm{TN})$ at DH. Thus, the difference in the resource use 


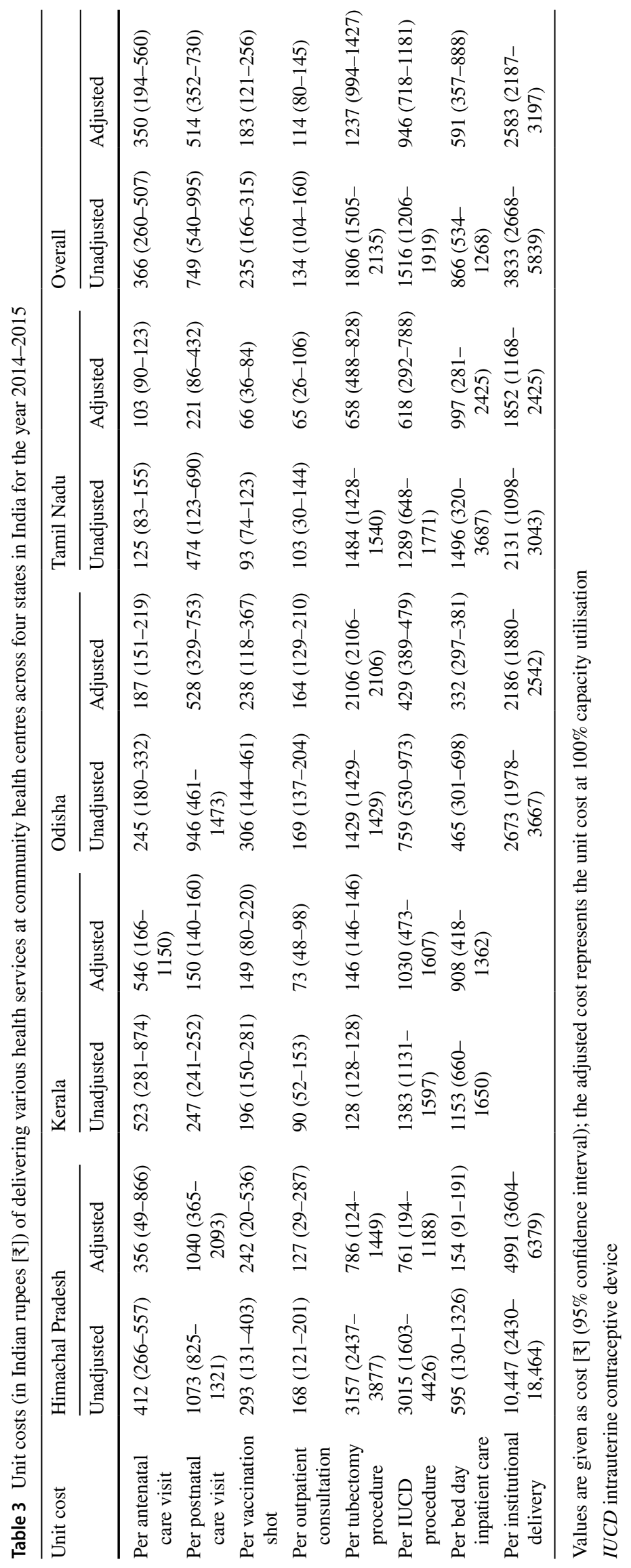




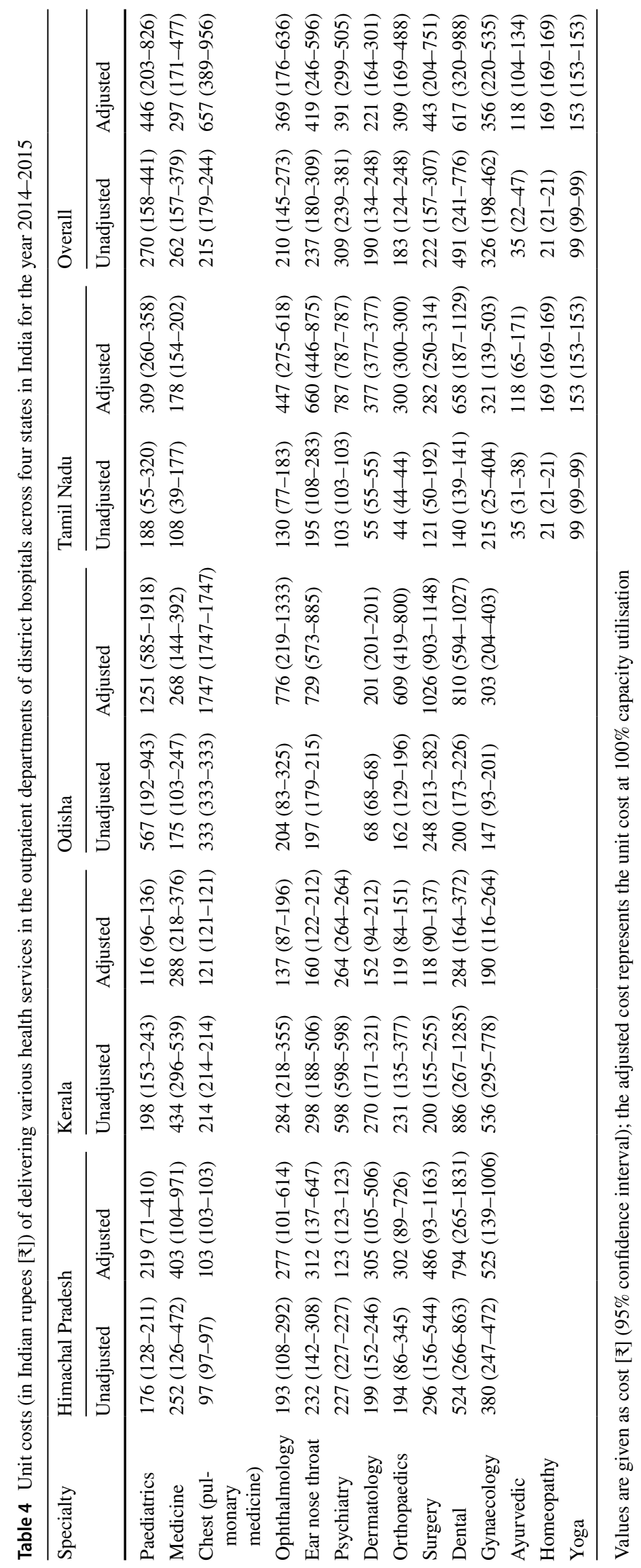




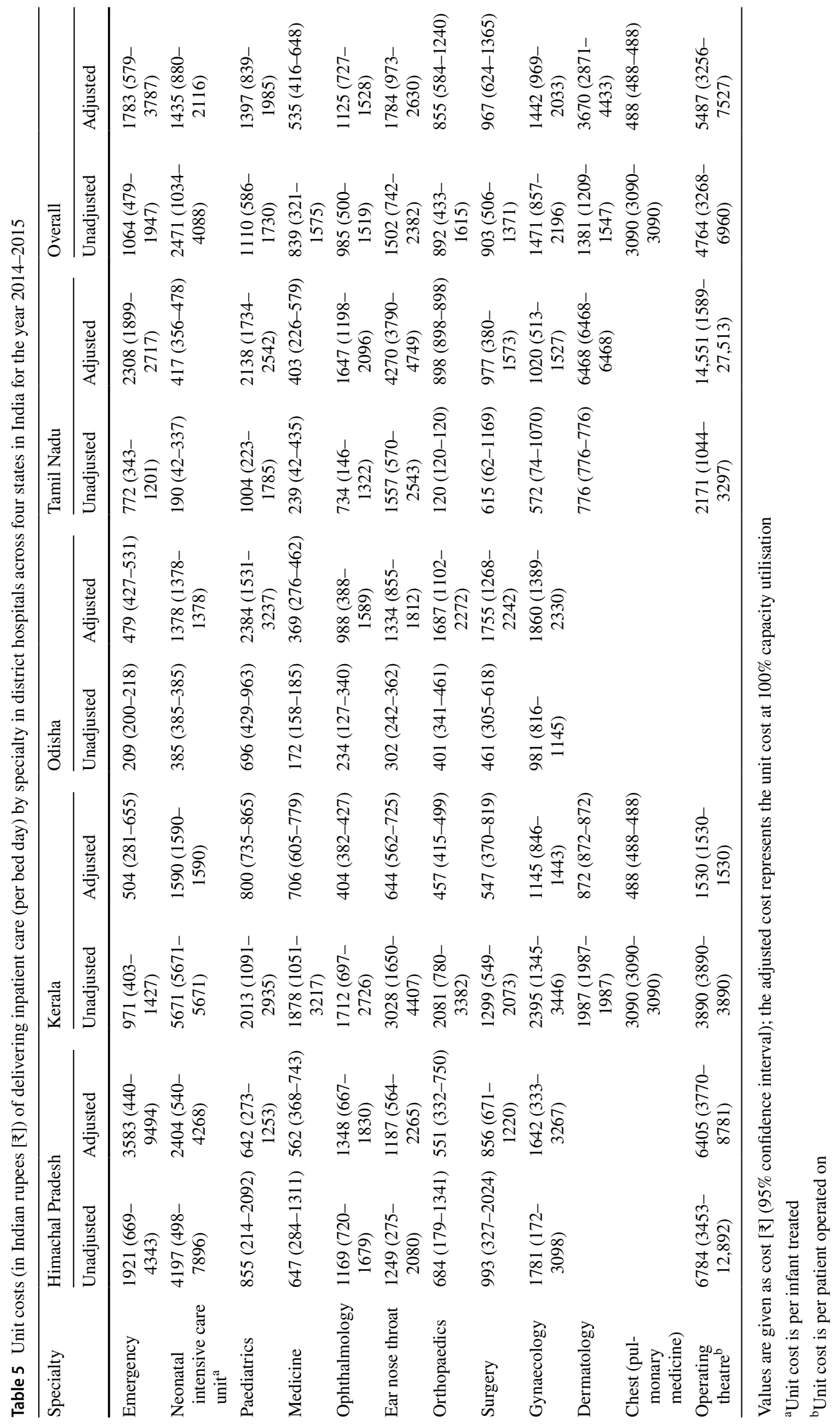


and the service utilisation across facilities played a major role in the disparity of unit costs.

We tried to adjust for differences in service utilisation by assessing standardised unit costs at $100 \%$ capacity utilisation. The bed occupancy rate was used as an indicator of capacity utilisation. As inpatient care is one of the best indicators reflecting the service load at facilities such as CHCs and DHs, the bed occupancy rate was considered to be suitable for adjustment for capacity utilisation $[1,33$, 34]. When calculating standardised unit costs, we adjusted for expenditure on drugs and other consumables, while keeping the expenditure on space, equipment and human resources constant. We recognise that time spent by human resources on various activities (based on the current levels of utilisation) is likely to increase or decrease as we adjust for capacity utilisation, and thus it would have an effect on the cost. When calculating the cost of human resources for various services, we have used the proportional amount of time spent by human resources in each of these services. Further, as we adjust for capacity utilisation, the overall time staff spent on various activities might increase or decrease, but the proportional time spent by them on various activities is expected to remain constant, assuming that any increase in service output will be similar for all types of services. In addition, as the number of staff members and their salary structure is bound to remain the same, the cost of human resources for various services is expected to remain the same as well.

As our estimates on total and unit costs are based on actual resource consumption and service utilisation, these are not representative of costs incurred in an ideal scenario. Facilities may be under- or over-resourced (as compared to IPHS norms), so may represent the current level of cost rather than ideal levels of cost. Specifically, the number of specialists stationed at the selected CHCs ranged from one to three doctors as compared to IPHS standard of four specialists at this level of health facility [2]. Furthermore, various studies across India have shown a high level of out-of-pocket (OOP) expenditure incurred on medicines at district-level facilities [35, 36], signifying a shortage of drugs. As our study did not assess OOP expenditure, we recommend undertaking future studies considering this resource gap and estimating the unit costs in an ideal scenario.

\subsection{Quality Assurance}

The data collection was regularly supervised and reviewed by state investigators. This included checking random entries with records and discussions with the heads of the health facilities included in the study. Following completion of the data collection, data cleaning and its completeness was assessed at the time of data entry. Missing entries, and other clarifications were identified and a review document was prepared. This document was then shared with the data collection team for the respective states and multiple electronic and telephonic communications took place to retrieve missing information and for data verification. In some cases, missing data for a variable in a health facility was imputed using mean/median values of the same variable as reported from the other facilities in the same state.

We identified key informants from each of the health facilities that were likely to have understanding and knowledge of the sources from where specific cost data elements could be obtained. These included data entry operators, pharmacists, accountants, administrative assistants and head nurses. The pharmacists, head nurses and data entry operators provided information on the quantity and consumption of both capital items and consumables as well as service utilisation The accountants and administrative assistants provided data on salaries and other expenditure-related data such as that on maintenance, overheads, meetings, training, etc.

\subsection{Limitations}

We would like to acknowledge that, considering the huge differences in infrastructure, wage rates and health system characteristics for a country as vast as India, the sample of states used in our study may not necessarily capture the entire heterogeneity of the health system. More research with a much wider coverage is required in the future to estimate a nationally representative average. However, given the federal structure of governance in India, and health being a state-level subject, state-level estimates of cost are more important than national-level averages. Moreover, as the predominant share of financing healthcare is borne by the state, decisions on allocation of resources, provider payments and procurement of resources are more at the state level. Our state-level estimates are valid given the sampling framework used within the state to choose the districts and health facilities. Further, we also recommend undertaking a cost-function analysis, which would help determine the effect of various explanatory factors on cost. In addition, this would help improve transferability of present study findings to other states.

We undertook personal interviews with staff members instead of robust time motion studies to assess the time spent on various activities, and acknowledge the credibility of time motion studies for assessing time allocation patterns. However, time motion studies are not able to capture time spent on infrequent fixed activities conducted over a shorter timeframe such as pulse polio immunisation, outreach camps, emergency duties, etc., which are likely to be missed by these observation methods. Further, our approach is justified as interview-based methods are easy, less costly 
to administer and also capture time spent on every activity. Previous health system costing studies in India have also used a similar methodology and cite these limitations [37, 38]. Data on resources such as overheads and the number of various services were available at a pooled level. We used standard apportioning statistics, as recommended in the literature [31], to apportion the cost of overheads among various services.

\section{Conclusion}

Overall, our study fills the current gap in evidence on the cost of secondary healthcare services delivered through public sector health facilities in India. The estimates from the present study are useful to aid in carrying out further research in the form of cost-effectiveness analysis, efficiency and equity analysis, benefit incidence analysis, etc., and these estimates can be used to generate national- or state-specific health accounts. The unit cost assessed in our study may not be directly used for estimating package or reimbursement rates for various health services delivered at the secondary care level; however, once OOP expenditure is added to the estimated health system unit costs reported here, the total unit cost can help generate some benchmarks to assist in beginning price negotiations to set up provider payment rates. Lack of robust information on cost of care has been identified as a major reason for appropriate provider payment rates, which leads to the practice of "balance billing' to patients by private providers. This becomes even more important with the implementation of the national health insurance-Prime Minister's Jan Arogya Yojana (PMJAY) [39]

Author Contributions SP, SS, VRM and TS conceptualised the study. ASC, SP, PB, VRM, TS and SS designed the methodology. ASC and $\mathrm{PB}$ carried out the acquisition of data. ASC, PB and SP interpreted the data and carried out the formal analysis. ASC and SP wrote the original draft. All authors revised the article critically for intellectual content. All authors read and approved the final manuscript.

Data Availability Statement Data on health system resources analysed during the current study are available from the corresponding author on reasonable request.

\section{Compliance with Ethical Standards}

Funding This research was supported by USAID India grant AID386-A-14-00006.

Conflict of interest Shankar Prinja, Akashdeep Singh Chauhan, Pankaj Bahuguna, Sakhtivel Selvaraj, V. R. Muraleedharan and Thiagarajan Sundararaman have no conflicts of interest directly relevant to the contents of this article.
Open Access This article is distributed under the terms of the Creative Commons Attribution-NonCommercial 4.0 International License (http://creativecommons.org/licenses/by-nc/4.0/), which permits any noncommercial use, distribution, and reproduction in any medium, provided you give appropriate credit to the original author(s) and the source, provide a link to the Creative Commons license, and indicate if changes were made.

\section{References}

1. Chokshi M, Patil B, Khanna R, Neogi SB, Sharma J, Paul VK, et al. Health systems in India. J Perinatol. 2016;36(Suppl 3):S9-12.

2. Government of India, Ministry of Health and Family Welfare, Directorate General of Health services. Indian Public Health Standards (IPHS) guidelines for community health centres: revised 2012. http://health.bih.nic.in/Docs/Guidelines/Guidelines -Community-Health-Centres.pdf. Accessed 15 Oct 2017.

3. Government of India, Ministry of Health and Family Welfare. Indian Public Health Standards, revised 2012: guidelines for district hospital (101 to 500 bedded). http://healthfacilityguidelines. com/Guidelines/ViewPDF/HFG-India/part_a5_district_hospital. Accessed 20 Oct 2017.

4. Kurian OC. Financing healthcare for all in India: towards a common goal. 2015. https://www.oxfamindia.org/sites/default/files/ WP-Financing-Healthcare-for-All-In-India-29-05-2015-EN_0. pdf. Accessed 10 Feb 2018.

5. Bowser D, Gupta J, Nandakumar A. The effect of demand- and supply-side health financing on infant, child, and maternal mortality in low- and middle-income countries. Health Syst Reform. 2016;2(2):147-59.

6. Government of India, Ministry of Health and Family Welfare. National health mission, national rural health mission. https:// www.nhm.gov.in/images/pdf/guidelines/nrhm-guidelines/missi on_document.pdf. Accessed 4 Sept 2018.

7. Government of India, Ministry of Health and Family Welfare. Health management information system: a digital initiative under national health mission. State/UT and district wise availability of health centres in India as on 31st March, 2016. https://data.gov. in/catalog/rural-health-statistics-2016. Accessed 20 Feb 2018.

8. Rashtriya Swasthya Bima Yojana. http://www.rsby.gov.in/. Accessed 20 Nov 2017.

9. Rajiv Gandhi Jeevandayee Arogya Yojana. https://www.jeeva ndayee.gov.in/. Accessed 17 Feb 2017.

10. Rajiv Aarogyasri Health Insurance Scheme. http://www.aarog yasri.telangana.gov.in/. Accessed 17 Feb 2017.

11. Government of India, Ministry of Health and Family Welfare, National Health Accounts Cell. National health accounts India, 2004-05. http://www.planningcommission.nic.in/reports/genre p/health/National_Health_Account_04_05.pdf. Accessed 20 Oct 2017.

12. Government of India, Ministry of Health and Family Welfare, National Health Systems Resource Centre, National Health Accounts Technical Secretariat. National health accounts: estimates for India 2014-15. https://mohfw.gov.in/sites/default/files /National\%20Health\%20Accounts\%20Estimates\%20Report\%20 2014-15.pdf. Accessed 15 Feb 2018.

13. Government of India. Ayushman Bharat; Pradhan Mantri Jan Arogya Yojana. Health benefit packages \& empanelment criteria for AB-NHPM. https://www.pmjay.gov.in/sites/default/files/2018-07/ HBP.pdf. Accessed 22 Jul 2019.

14. Prinja S, Chauhan AS, Karan A, Kaur G, Kumar R. Impact of publicly financed health insurance schemes on healthcare utilization 
and financial risk protection in India: a systematic review. PLoS One. 2017;12(2):e0170996.

15. World Health Organization. Choosing Interventions that are Cost-Effective (WHO CHOICE): results for unit costs for patient services for 14 GBD regions. Geneva: World Health Organization; 2005. https://www.who.int/choice/costs/unit_regions/en/. Accessed 15 Sep 2018.

16. Government of India, Ministry of Health and Family Welfare. Report of the National Commission on Macroeconomics and Health. New Delhi, India. 2005. https://www.who.int/macrohealt h/action/Report\%20of\%20the\%20National\%20Commission.pdf. Accessed 23 Mar 2018.

17. Chatterjee S, Levin C, Laxminarayan R. Unit cost of medical services at different hospitals in India. PLoS One. 2013;8(7):e69728.

18. Prinja S, Balasubramanian D, Jeet G, Verma R, Kumar D, Bahuguna $\mathrm{P}$, et al. Cost of delivering secondary-level health care services through public sector district hospitals in India. Indian J Med Res. 2017;146(3):354-61.

19. Prinja S, Gupta A, Verma R, Bahuguna P, Kumar D, Kaur M, et al. Cost of delivering health care services in public sector primary and community health centres in North India. PLoS One. 2016;11(8):e0160986.

20. NITI Aayog, Ministry of Health and Family Welfare. Health states, progressive india: report on the ranks of states and union territories. http://social.niti.gov.in/uploads/sample/health_index report.pdf. Accessed 19 Mar 2018.

21. Purohit BC. Health care system efficiency: a sub state level analysis for Orissa (India). Rev Urb Reg Dev Stud. 2016;28(1):55-74.

22. Taqi M, Bidhuri S, Sarkar S, Ahmad W, Wangchok P. Rural healthcare infrastructural disparities in India: a critical analysis of availability and accessibility. J Multidiscip Res Healthc. 2017;3(2):125-49.

23. Government of India, Ministry of Health and Family Welfare, National Health Systems Resource Centre, National Health Accounts Technical Secretariat. National health accounts: estimates for India 2015-16. http://nhsrcindia.org/sites/default/files/ NHA\%20Estimates\%20Report\%20-\%20November\%202018.pdf. Accessed 19 Jun 2019.

24. Government of India, Ministry of Statistics and Programme Implementation. NSSO 71st Round (January-June 2014): key indicators of social consumption in India health. New Delhi: Minitry of Statistics and Program Implementation; 2015.

25. Goverment of India, Ministry of Health and Family Welfare. Rural health statistics in India, a digital india initiative. District-wise availability of health centres in India as on 31st March, 2017. https://data.gov.in/resources/district-wise-availability-health-centr es-india-31st-march-2017. Accessed 20 Jul 2019.
26. Ram F, Shekhar C. Ranking and mapping of districts: based on socio-economic and demographic indicators 2006. http://iipsindia. org/pdf/05_b_13acp.pdf. Accessed 5 Dec 2017.

27. Chapko MK, Liu CF, Perkins M, Li YF, Fortney JC, Maciejewski ML. Equivalence of two healthcare costing methods: bottom-up and top-down. Health Econ. 2009;18(10):1188-201.

28. Waters HR, Hussey P. Pricing health services for purchasers-a review of methods and experiences. Health Policy. 2004;70(2):175-84.

29. Drummond ME, Stoddard GL, Torrance GW. Methods for the economic evaluation of health care programmes. 1st ed. Oxford: Oxford University Press; 1987.

30. Walker D, Kumaranayake L. Allowing for differential timing in cost analyses: discounting and annualization. Health Policy Plan. 2002;17(1):112-8.

31. Fox-Rushby J, Cairns J. Economic evaluation. London: Oxford University Press; 2006.

32. World Health Organization. Making choices in health: WHO guide to cost-effectiveness analysis. Geneva: World Health Organization; 2003. https://www.who.int/choice/publications/p_2003_ generalised_cea.pdf. Accessed 4 Aug 2018.

33. Adhikari SR, Sapkota VP, Supakankunti S. A new approach of measuring hospital performance for low- and middle-income countries. J Korean Med Sci. 2015;30(Suppl 2):S143-8.

34. Pandve HT, Giri PA. First referral units (FRU): needs focus in Indian context. Int $\mathbf{J}$ Community Med Public Health. 2015;2(2):75-6.

35. Selvaraj S, Karan A. Why publicly-financed health insurance schemes are ineffective in providing financial risk protection. Econ Polit Wkly. 2012;47:60-8.

36. Prinja $S$, Kanavos $P$, Kumar R. Inequities in health care utilization in three north Indian states: role of public sector in universalizing health care. Indian J Med Res. 2012;136:421-31.

37. Prinja S, Jeet G, Verma R, Kumar D, Bahuguna P, Kaur M, et al. Economic analysis of delivering primary health care services through community health workers in 3 North Indian states. PLoS One. 2014;9:e91781.

38. Prinja S, Mazumder S, Taneja S, Bahuguna P, Bhandari N, Mohan $\mathrm{P}$, et al. Cost of delivering child health care through community level health workers: how much extra does IMNCI program cost? J Trop Pediatr. 2013;59:489-90.

39. Angell BJ, Prinja S, Gupt A, Jha V, Jan S. The Ayushman Bharat Pradhan Mantri Jan Arogya Yojana and the path to universal health coverage in India: overcoming the challenges of stewardship and governance. PLoS Med. 2019;16(3):e1002759. 